\section{Index of decline of British science}

SIR - Nature has an 'impact factor' almost ten times greater than that of other journals; so those working at the leading edge of science try to publish in it. As Nature has offices in Tokyo, Munich, Washington and London, it should provide a good sample of world science. This letter is an analysis of Letters published in Nature since 1978 to see if trends could be identified; for these might be an early indication of the future health of science in the countries studied.

Results were analysed separately for the physical and biological sciences. The figure shows that the percentage of letters in each section originating in the United Kingdom in 1989 has fallen to about half that in 1978, whereas those from the United States, France, Germany and Japan have increased. The number of
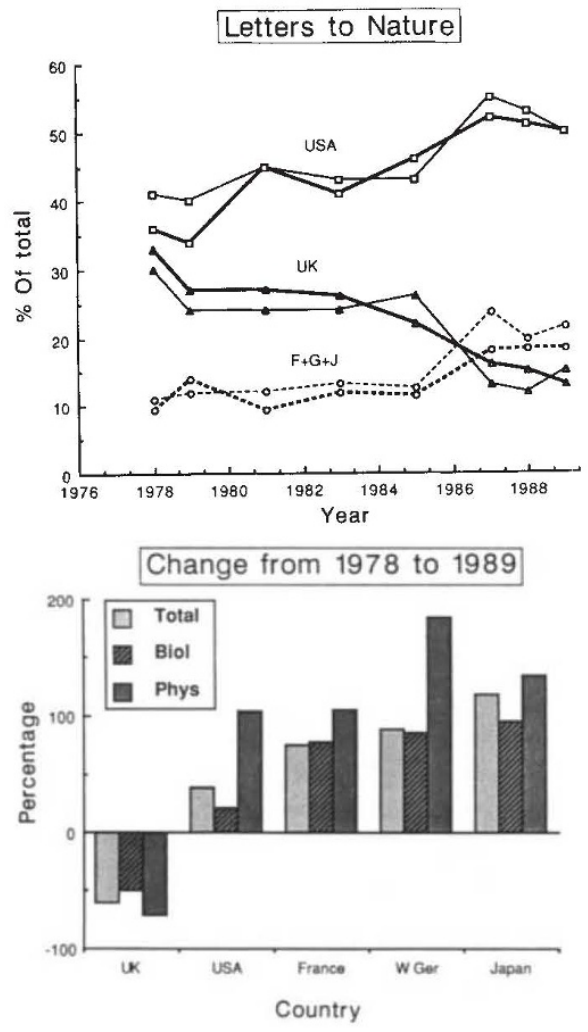

The upper part shows the percentage of all (dark lines) or 'biological' letters originating in the indicated countries. Those from France, Germany and Japan, all rising, have been added. The lower part shows the percentage change for each country from 1978 to 1989 , as total, biological or physical. 'Letters to Nature' in the first five issues of eight of the years from 1978 to 1989 were categorized into physical or biological sciences, and their country of origin apportioned according to the addresses given by the authors. Because of the small numbers involved, only those from the United Kingdom, the United States, France, West Germany and Japan were counted separately. The total sample size for each year was around 100, making up about 10 per cent of each year's total. letters from the United Kingdom and the United States is now roughly proportional to their populations. The large rise in those from Japan does not support the view that the Japanese are uninterested in basic science. The type of biology letter published seems to have changed with time: the early ones described results obtained with simple equipment, whereas many of the later ones describe the sequences of DNA and other molecules, results requiring large machines and an infrastructure to run them. The abrupt drop in the biology letters from the United Kingdom starting around 1985 may reflect this change in the expense of modern biology and the inadequacy of our current level of funding.

A detailed examination of the subset of results published in high quality journals such as Nature might provide better evidence for the present state of science in various countries than the blanket approach currently used.

MRC Clinical Pharmacology Unit, J. F. LAMB

Clinical Pharmacology,

Radcliffe Infirmary,

Woodstock Road, Oxford OX2 6HE, UK

\section{Problems of South Africa}

SIR-It is unfortunate that the Commentary by File et al. on South African education (Nature 341, 96; 1989) was immediately followed by a letter from $\mathrm{Mr}$ John Ormerod (341, 99; 1989) supporting an academic boycott of South African science. The crying need there is for some sort of 'constructive engagement' that seeks development along internationally acceptable lines. The black leaders that Ormerod hears in Oslo may see political power as paramount, but the heart of the toyi-toyi (demonstration) knows that political gain will count for little without equality of educational and economic opportunities. As your article shows, it is still the universities designated as black that contribute most to correcting this imbalance in the tertiary sector, yet it is precisely these institutions that will suffer most from the effects of such a boycott, as the liberal white universities, already excellent self-publicists, will readily find ways to avoid them, while the Afrikaners simply do not care.

My fear regarding "People's Education", with its emphasis on community relevance, is that it will deny black scientists any participation in science sufficiently fundamental or challenging to let them feel a part of a wider scientific community. The result would in effect be a
University Department of self-imposed racial stereotype, but it would be accepted without qualms by white South Africans, as the liberals would see it as giving the people what they want, the verkrampt (conservative) as giving blacks what they deserve. Unless outsiders like myself prevent the isolation of South African science by boycott, this damaging insularity will have become eradicable by the post-apartheid era. If anyone really wishes to "stick his neck out" on the role of scientists in this particular conflict, I can readily find him a place beside me on the front line.

JOHN S. RUTHERFORD

Faculty of Science,

University of Transkei,

Private Bag XI,

Umtata,

Republic of Transkei

SIR-There are several inaccuracies in Michael Cherry's article on the South African research budget (Nature 342, 605; 1989).

The national laboratories of the Council for Scientific and Industrial Research (CSIR) were never taken away from the Foundation for Research Development (FRD), because the FRD has never maintained its own laboratories; it is a funding body and not a research organization. There has not been a shift of emphasis from basic to applied research within the FRD; in fact the lion's share of funding still goes to the core programme which mostly supports basic research. Minister Gerrit Viljoen has not gone on record in favour of either basic or applied research. The National Accelerator Centre's budget is nowhere near 34 per cent of the CSIR's budget. It is, in fact, 6.7 per cent of the total budget.

\section{Council for Scientific and}

C. F. GARBERS

\section{Industrial Research,}

\section{PO Box 395}

Pretoria 0001,

South Africa

- The errors of which Dr Garbers complains were introduced in the sub-editing of this story for publication. - Editor, Nature.

\section{The coming ice age}

SIR - The study of the oxygen-18 content of the $\mathrm{CaCO}_{3}$ shells of marine organisms by, for example, Emiliani (Science 202, $627 ; 1978$ ) has shown convincingly that we are living at the zenith of the present Interglacial. The presence of an atmospheric $\mathrm{CO}_{2}$ blanket should therefore be considered as a blessing for the coming 50,000 years.

Antw. Steenw. 915

A. J. RUTGERS 